\title{
PPARs in Human Neuroepithelial Tumors: PPAR Ligands as Anticancer Therapies for the Most Common Human Neuroepithelial Tumors
}

\author{
Elisabetta Benedetti, ${ }^{1}$ Renato Galzio, ${ }^{2}$ Barbara D'Angelo, ${ }^{1}$ Maria Paola Cerù, ${ }^{1}$ \\ and Annamaria Cimini ${ }^{1}$ \\ ${ }^{1}$ Department of Basic and Applied Biology, University of L'Aquila, 67100 L'Aquila, Italy \\ ${ }^{2}$ Department of Health Sciences (Neurosurgery), University of L'Aquila, 67100 L'Aquila, Italy \\ Correspondence should be addressed to Annamaria Cimini, cimini@univaq.it
}

Received 30 September 2009; Revised 14 December 2009; Accepted 11 February 2010

Academic Editor: Michael E. Robbins

Copyright () 2010 Elisabetta Benedetti et al. This is an open access article distributed under the Creative Commons Attribution License, which permits unrestricted use, distribution, and reproduction in any medium, provided the original work is properly cited.

\begin{abstract}
Neuroepithelial tumors represent a heterogeneous class of human tumors including benignant and malignant tumors. The incidence of central nervous system neoplasms ranges from 3.8 to 5.1 cases per 100,000 in the population. Among malignant neuroepithelial tumors, with regard to PPAR ligands, the most extensively studied were tumors of astrocytic origin and neuroblastoma. PPARs are expressed in developing and adult neuroepithelial cells, even if with different localization and relative abundance. The majority of malignant neuroepithelial tumors have poor prognosis and do not respond to conventional therapeutic protocols, therefore, new therapeutic approaches are needed. Natural and synthetic PPAR ligands may represent a starting point for the formulation of new therapeutic approaches to be used as coadjuvants to the standard therapeutic protocols. This review will focus on the major studies dealing with PPAR expression in gliomas and neuroblastoma and the therapeutic implications of using PPAR agonists for the treatment of these neoplasms.
\end{abstract}

\section{Neuroepithelial Tumors}

Human neuroepithelial tumors are classified according the World Health Organization (WHO). The incidence of central nervous system (CNS) neoplasms ranges from 3.8 to 5.1 cases per 100,000 in the population. Among neuroepithelial tumors, with regard to PPAR ligands, the most extensively studied are tumors of astrocytic origin and neuroblastoma.

Astrocytic tumors are classified as: (1) Astrocytoma (WHO grade II), (2) Anaplastic (malignant) astrocytoma (WHO grade III), (3) Glioblastoma multiforme (WHO grade IV); (4) Pilocytic astrocytoma noninvasive, (WHO grade I), (5) Subependymal giant cell astrocytoma (noninvasive, WHO grade I), (6) Pleomorphic xanthoastrocytoma (noninvasive, WHO grade I) [1-4].

Malignant astrocytic tumors are the most common primary brain tumors. High-grade gliomas show high cellular proliferation rate and infiltrate the adjacent brain tissue [5]. They initially respond to radiation and, to a lesser degree, to chemotherapy; however, they invariably recur. The malignant gliomas with poor prognosis and fatal outcome are mainly represented by anaplastic astrocytoma and glioblastoma.

1.1. Anaplastic Astrocytoma (WHO Grade III). Also known as malignant astrocytoma and high-grade astrocytoma, it may arise from a diffuse astrocytoma or may arise de novo without indication of a less malignant precursor [6]. Histologically, these tumors show increased cellularity, distinct nuclear atypia, and marked mitotic activity when compared with low-grade astrocytomas. Anaplastic astrocytomas possess an intrinsic tendency to progress to glioblastoma. The mean age at diagnosis is approximately 41 years. This tumor primarily affects the cerebral hemispheres. It has a high frequency of TP53 mutations, which 
is similar to that of low-grade astrocytomas; chromosomal abnormalities are nonspecific. Many of the genetic alterations seen in anaplastic astrocytomas involve genes that regulate cell cycle progression [4]. The mean time to progression is 2 years. Positive predictive factors include young age, high performance status, and gross total tumor resection.

1.2. Glioblastoma (WHO Grade IV). Also known as glioblastoma multiforme (GBM), it may develop from low-grade astrocytomas or anaplastic astrocytomas but more commonly it arises de novo without evidence of a less malignant precursor [7]. GBM, the most common malignant brain tumor $(34 \%)$ in adults, is among the most lethal of all cancers [8]. Histologically, GBMs are anaplastic, cellular gliomas composed of poorly differentiated, often pleiomorphic astrocytic tumor cells with marked nuclear atypia and brisk mitotic activity. Typically, they affect adults and are preferentially located in cerebral hemispheres. Most patients with GBM survive less than 1 year, thus new therapeutic strategies are urgently needed $[9,10]$. Genetic analyses suggest that there are two different types of glioblastoma: de novo glioblastoma, which arises from mutated neural stem cells or progenitor cells, and secondary glioblastoma, which arises from lower grade tumors. The secondary GBMs occur in younger patients [11-13]. The peak incidence occurs between the ages of 45 and 70 years. GBMs have been associated with more specific genetic abnormalities than any other astrocytic neoplasm, but none are specific. Amplification of the epidermal growth factor receptor locus is found in approximately $40 \%$ of primary GBMs but is rarely found in secondary glioblastomas; mutations of the PTEN gene are observed in $45 \%$ of primary GBMs and to a lesser extent in secondary glioblastomas [4]. Loss of heterozygosity (LOH) of chromosome 10 and loss of an entire copy of chromosome 10 are the most frequently observed chromosomal alterations.

1.3. Neuroblastoma. Neuroblastomas are paediatric tumors originating from neuroblasts in the developing peripheral nervous system. Most primary tumors $(65 \%)$ occur within the abdomen, with at least half of these arising in the adrenal medulla. Other common sites of disease include the neck, chest, and pelvis. It is the most common extracranial solid tumor in childhood and the most frequently diagnosed neoplasm during infancy [14]. Neuroblastoma accounts for more than $7 \%$ of malignancies in patients younger than 15 years and around $15 \%$ of paediatric deaths [15]. The mortality is high due to rapid tumor progression to advanced stages. The genetic aberration most consistently associated with poor outcome in neuroblastoma is genomic amplification of MYCN, which occurs in roughly $20 \%$ of primary tumors and is strongly correlated with advanced stage of disease and treatment failure $[14,16,17]$. Deletions of the short arm of chromosome 1 (1p) can be identified in $25-35 \%$ of neuroblastomas. These deletions correlate not only with MYCN amplification, but also with advanced disease stage $[18,19]$. However, the gene or genes within chromosome
$1 \mathrm{p}$ involved in the pathogenesis of neuroblastoma have not been identified despite intensive investigation. It has been suggested that a strategy to halt the malignancy of these cells could be to induce them to differentiate towards mature neurons. Accordingly, several neuroblastoma differentiation protocols have been proposed, for instance treatment with phenyl acetate and retinoic acid [20]. The SH-SY5Y cell line was established from a high malignant tumor with no $\mathrm{N}$-myc amplification [21]. Treatment of this cell line with phorbol esters leads to sympathetic neuronal differentiation with neurite outgrowth and increased synthesis of noradrenaline and expression of neuropeptide $\mathrm{Y}$ and growth-associated protein 43 (GAP-43) [22]. These effects are mediated by and dependent on PKC $[20,23,24]$.

1.4. PPARs. The peroxisome proliferator-activated receptor (PPAR) family of nuclear receptors are ligand-activated transcription factors which have been implicated in different human pathologies. PPAR $y$ ligands are currently used for treatment of type II diabetes, PPAR $\alpha$ ligands are used to treat cardiovascular diseases [25-27]. After the isolation of PPAR $\alpha$ (NR1C1), in 1990 by Issemann and Green [28] as the nuclear receptor mediating peroxisome proliferation by peroxisome proliferators (PP) in rodent hepatocytes, two related isotypes, $\mathrm{PPAR} \beta / \delta$ (NR1C2; referred to as PPAR $\beta$ ) and PPARy (NR1C3) have been characterized [29]. Since then, these receptors have been linked to many systemic and cellular functions ranging far beyond the process after which they were initially named. Like the other members of the superfamily, PPARs have a canonical nuclear receptor organization [30]. The DNA-binding domain, named the C domain, is highly conserved and its zinc finger domain is a common attribute of all members of the nuclear receptor (NR) superfamily. The $\mathrm{C}$ domain is linked to the C-terminal ligand-binding domain ( $\mathrm{LBD}$ ), named the $\mathrm{E}$ domain, by the hinge region, named the $\mathrm{D}$ domain. The LBD contains a ligand-dependent transactivation function referred to as AF- 2 and comprises $12 \alpha$ helices and $4 \beta$ sheets that fold to create a large hydrophobic cavity where ligands are buried [31]. In addition, the $\mathrm{E}$ domain offers the main surface for dimerization with the 9-cis retinoic acid receptor (RXR) as well as for interaction with regulatory proteins called cofactors. The N-terminal domain, named the $\mathrm{A} / \mathrm{B}$ domain, is involved in ligand-independent regulation of receptor activity [32]; this domain harbors a weak-ligandindependent transactivation function, called AF-1. PPARs form heterodimers with the RXR and exhibit ligand-induced transcriptional regulatory activity through sequence-specific PPAR-responsive elements (PPRE) in their target genes [33]. Free PPARs may be associated with corepressors that inactivate the transcription function of the nuclear receptor. When the nuclear receptor is activated by a particular ligand binding to the ligand binding domain, this results in conformational changes to PPAR, and the receptor is released from binding with the corepressor. PPAR forms a heterodimeric complex with RXR and then recruits coactivator proteins. This complex binds to a PPRE on DNA and regulates transcription. Peroxisome proliferators, like fatty acids, modulate 
tissue-specific responses; for example, they stimulate the expression of enzymes involved in lipid catabolism, namely, the peroxisomal $\beta$-oxidation system $[34,35]$.

PPARs exhibit a broad but isotype-specific tissue expression pattern which can account for the variety of cellular functions they regulate. PPAR $\alpha$ and $\gamma$ transcripts appear late during fetal development of rat and mouse (day 13.5 of gestation), with a pattern of expression similar to their adult distribution, with the exception of the placenta tissue, where PPAR $\gamma$ is abundantly expressed as early as E8.5 [36, 37]. It has been demonstrated that PPAR $\gamma$ functions in the placenta are crucial for trophoblast terminal differentiation and consequently for placental vascularization and integrity [37]. In the adipose tissue, the two PPAR $\gamma$ isoforms, $\gamma 1$ and $\gamma 2$, act in the brown and white tissues, respectively, to promote adipocyte differentiation and lipid storage, while the expression of the PPAR $\gamma 1$ is preferentially shown in other tissues such as the gut or the immune cells [38]. PPAR $\alpha$ is expressed in tissues with high fatty acid catabolism such as the liver, heart, skeletal muscle, adrenal gland and pancreas, kidney, and intestine. In comparison with the two other isotypes, PPAR $\beta / \delta$ is expressed more ubiquitously and earlier during fetal development [39]. Its transcript is present in all organ tested, and it is often more abundant than the PPAR $\alpha$ and $\gamma$ transcripts [40]. Shi et al. and Bastie have suggested the involvement of unliganded $\operatorname{PPAR} \beta / \delta$ in modulating the expression and transcriptional activity of the other two PPARs [41, 42]. In addition, it has been shown that it is required for placenta development, in the control of cell proliferation and survival, especially in keratinocytes and enterocytes, and in the control of lipid metabolism, even though the underlying mechanisms still need investigations [43].

For more than a decade, work on PPARs was driven by their important role in the regulation of cellular metabolism, PPAR $\alpha$ in tissues known for high $\beta$-oxidation rates such as liver, heart, muscle, and kidney [44], while PPAR $\gamma$ was mainly studied for its adipogenic activity. At present, they are receiving growing attention for their involvement in the regulation of cell proliferation, death, and differentiation of both normal and malignant cells.

1.5. PPAR Ligands. PPARs are activated by a wide range of naturally occurring or metabolically produced lipids derived from the diet or from endogenous lipid molecules functioning in intracellular signalling pathways, which include saturated and unsaturated fatty acids and fatty acid derivatives such as prostaglandins and leukotrienes [45]. Whereas most natural agonists bind with a relatively weak affinity (in the order of -molar concentration), some high-affinity endogenous ligands have been characterized [46, 47]. Interestingly, some ligands, including 15-deoxy-prostaglandin J2 (15d-PGJ2), associate irreversibly to the receptor through covalent binding [48]. The delivery of PPAR ligands to the nucleus, where the receptors reside, is achieved by different cellular fatty acid binding proteins (FABPs), which are thought to specifically interact with the three PPAR isotypes [49]. PPAR $\alpha$ agonists include both fibrates commonly used for the treatment of hypertriglyceridemia and the synthetic agonists WY 14,643 and GW7647. The best-characterized PPAR $\gamma$ agonists are thiazolidinediones (TZDs), including pioglitazone and rosiglitazone, which have insulin sensitizing activity and are currently used for the treatment of type 2 diabetes (Actos and Avandia, respectively) [44]. There are a number of nonTZD based PPAR $\gamma$ agonists, such as GW347845 and others that have been synthesized.

Apart from well-defined metabolic actions, PPAR $y$ agonists exhibit several antineoplastic effects [50] and induce apoptotic cell death in various malignant cell lineages, including liposarcoma [51], breast adenocarcinoma [52, 53], prostate carcinoma [54], colorectal carcinoma [55, 56], nonsmall-cell lung carcinoma [57], pancreatic carcinoma [58], bladder cancer [59], and gastric carcinoma [60].

$\operatorname{PPAR} \beta / \delta$ agonists include the prostacyclin $\mathrm{PGI}_{2}$, oleic acid, and the agents, GW0742, GW501516 and GW7842.

\section{PPARs in the Brain}

All three PPAR isotypes are coexpressed in the rat CNS during late embryogenesis, with $\mathrm{PPAR} \beta / \delta$ being the more abundantly and precociously expressed. The expression of the three PPAR isotypes peaks in the rat CNS between day 13.5 and 18.5 of gestation. Whereas $\operatorname{PPAR} \beta / \delta$ remains highly expressed, the expression of PPAR $\alpha$ and PPAR $\gamma$ decreases postnatally in the brain [61]. Both in vitro and in vivo observations show that PPAR $\beta / \delta$ is the prevalent isoform in the brain, found in all nervous cell types, whereas PPAR $\alpha$ is expressed at very low levels predominantly in astrocytes [30]. Acyl-CoA synthetase 2 (ACS2), an enzyme crucial for fatty acid activation and utilization, is regulated by $\operatorname{PPAR} \beta / \delta$ at the transcriptional level, providing a simple measure of $\operatorname{PPAR} \beta / \delta$ action [62]. ACS2 has a role in maturation of neurons (i.e., their cytodifferentiation and formation of neuronal connectivity); in addition, its over-expression in PC12 cells enhances internalization of fatty acids, namely oleic acid (OA), arachidonic acid (AA), and docosahexaenoic acid (DHA) and promotes neurite outgrowth [63]. These observations strongly suggest that $\operatorname{PPAR} \beta / \delta$ participates in the regulation of lipid metabolism in the brain, a hypothesis further supported by the observation that $\operatorname{PPAR} \beta / \delta$ null mice exhibit an altered myelination of the corpus callosum [64]. The fact that no cytoarchitectural alterations of cerebral cortex was described is in contrast with the results obtained by Michalik et al. and Cimini et al., demonstrating the existence of a close correlation between PPAR $\beta / \delta$ and ACS2 in PPAR $\beta / \delta$ null mice brain and in the rat cortical neurons, respectively $[65,66]$. However, the study from Peters et al. is a mainly in situ study and may be only in apparent contrast with other authors because it does not exclude that neuronal function and competence may be impaired in $\operatorname{PPAR} \beta / \delta$ null mice [64].

All PPARs have been described in the adult and developing brain and spinal cord [67-69]. While $\operatorname{PPAR} \beta / \delta$ has been found in neurons of numerous brain areas, PPAR $\alpha$ and PPAR $\gamma$ have been localized to more restricted brain areas $[67,68]$. The localization of PPARs has been also 
investigated in purified cultures of neural cells. Previous studies have reported that $\mathrm{PPAR} \beta / \delta$ is strongly expressed in immature oligodendrocytes $(\mathrm{OL})$ where its activation promotes differentiation; PPAR $\gamma$ is mainly present in microglia, while astrocytes possess all three PPAR isotypes, although to different degrees depending on the brain area and animal age [70-74]. The role of PPARs in the CNS has mainly been related to lipid metabolism but these receptors have been recently implicated in neural cell differentiation and death as well as in inflammation and neurodegeneration [36]. PPAR $\alpha$ has been suggested to be involved in astrocyte maturation and differentiation both in primary adult mouse astroglial cells and in adult neural stem cells (NSC) [75-77]. In addition, this isotype has been suggested to be involved in acetylcholine metabolism and oxidative stress defense $[68,78]$.

PPAR $\gamma$, besides playing a role in early phases of oligodendrocyte differentiation, has been mainly studied in relation to inflammation, cancer, and neurodegeneration [79]. Concerning $\operatorname{PPAR} \beta / \delta$, its involvement in neuronal differentiation and in CNS development has been suggested by Basu-Modak et al., Michalik et al., Braissant and Whali, on the basis of its high levels in rat neural tube, in reaggregated neural cell cultures and in adult CNS $[62,65,80]$. Roles for PPAR $\beta / \delta$ in the regulation of pain sensation and transmission in adult spinal cord [69] and in learning and memory in mouse hippocampus and in entorhinal cortex have been proposed $[67,69]$. In a previous work we showed that $\operatorname{PPAR} \beta / \delta$ is the main isotype present in primary cultures of rat cortical neurons, where it seems necessary for neuronal maturation together with the reduction of PPAR $\gamma$ expression and the activation of PPAR $\alpha$; $\operatorname{PAR} \beta / \delta$, in fact, is gradually increased and activated during neuronal maturation, and this increase correlates with the expression of its target gene ACS2 [81].

\section{PPARs in Neuroepithelial Tumors}

Among neuroepithelial tumors, gliomas, especially glioblastoma and neuroblastoma, have been the most extensively studied as to regard PPARs, and in this context, the PPAR $\gamma$ isotype was the most extensively studied.

3.1. PPARs and GBM. Glioblastoma expresses all three PPAR isotypes both in vitro and in situ. The majority of the studies performed on this neoplasm, both on rat and human gliomas, reported on the antiproliferative activity of different PPARy ligands, both natural and synthetic, by promoting apoptotic cell death or by increasing reactive oxygen species production [82-86]. PPAR $y$ has been identified in transformed neural cells of human origin, and PPAR $y$ agonists have been shown to decrease cell proliferation, stimulate apoptosis, and induce morphological changes as well as expression of markers typical of a more differentiated phenotype in glioblastoma and astrocytoma cell lines [87-89]. These findings have more recently been confirmed in glioblastoma primary cultures; treating pri- mary cultures of gliobalstoma cells with natural or synthetic PPAR $y$ ligands decreases the expression of markers of undifferentiated stages, such as CD133, nestin and fibronectin, while increasing the expression of differentiation markers such as A2B5, GFAP, $\beta$-catenin, and $\mathrm{N}$-cadherin. Conjugated linoleic acid (CLA) and the PPAR $\gamma$ synthetic agonist GW347845 also suppress proliferation and induce apoptosis in primary cultures of glioblastoma cells [90]. Consistent with growth inhibition, both ligands downregulate cyclinD1 and $\mathrm{CDk} 4$ protein levels, while inducing the transcription of the tumor suppressor gene PTEN. Both CLA and PPAR $\gamma$ agonist lead to a significant decrease of the VEGF isoforms and NOSII, thus indicating that even in glioblastoma PPAR $\gamma$ is able to inhibit the angiogenic pathways [90]. It has also been reported that ciglitazone induces apoptosis in four human glioblastoma cell lines by decreasing cyclin D1 and $\mathrm{Bcl}-2$ proteins and increasing $\mathrm{p} 27$ and $\mathrm{p} 21$ proteins $[91,92]$. Finally, there is some evidence to suggest that TZDs are potent inhibitors of glioma cell migration and brain invasion largely by transcriptional repression of TGF$\beta$ [93]. This is particularly important because TGF- $\beta$ is an immunosuppressive cytokine that has been shown to play a major role in the malignant phenotype of gliomas [94]. Furthermore, inhibition of TGF- $\beta$ signaling restores immune surveillance and is associated with improved survival in a glioma model [95].

Apoptosis-based therapies gained interest as promising experimental treatment strategies since direct induction of apoptotic cell death can overcome many of the classical resistance mechanisms such as activated DNA repair or detoxification. The death ligand TRAIL/Apo2L might be a useful tool to trigger apoptosis in cancer, since TRAIL kills tumor cells of diverse cellular origin without severe toxic side effects $[96,97]$. However, despite the common expression of death receptors, not all glioblastoma cells are susceptible to TRAIL, due to intracellular blockage of apoptotic signalling cascades. A group of PPAR $\gamma$-modulating agents sensitize tumor cells to TRAIL-induced apoptosis [98]. It has been reported that glioblastoma cells are sensitized to TRAILinduced apoptosis by troglitazone via various mechanisms. Troglitazone lead to a marked down-regulation of the antiapoptotic proteins FLIP and Survivin. Moreover, in some cell lines, the cell surface expression of agonistic and antagonistic TRAIL receptors was altered towards a higher susceptibility to death receptor-induced apoptosis. Troglitazone might counteract the capability of tumor cells to become resistant to apoptosis by modulating the apoptotic machinery at different levels [98].

It should be noted that only PPAR $\gamma$ ligands have been described as antiproliferative compounds in gliomas; no effects have been reported for other PPAR ligands. However, some evidences, obtained by us [99] in human gliomas at different grades of malignancy, strongly indicate an upregulation of PPAR $\alpha$ and its direct relationship with malignancy grade, suggesting that PPAR $\alpha$ antagonists can be used to halt malignancy, and suggesting that in some cases dual PPAR agonists should be carefully used.

Taken together, these data reported in glioma cells indicate that PPAR $y$ activation by both synthetic and natural 
ligands, results in cell cycle arrest, apoptosis promotion, inhibition of cell migration and invasion as well as suppression of antiapoptotic proteins, induction of differentiation markers, thus suggesting their potential use in the formulation of new therapeutic strategies against this neoplasm and recurrences.

3.2. PPARs and Neuroblastoma. Neuroblastoma cells express all three isotypes of PPARs. PPAR $y$ is present in neuroblastoma cell lines [100], as well as in primary neuroblastoma cell culture [50]. Few studies report the expression of PPAR $\alpha$ at mRNA or protein level in human neuroblastoma cell lines [101] and data on the expression of $\operatorname{PPAR} \beta / \delta$ in neuroblastomas are scarce [102]. To assess the roles of PPARs on neuroblastoma, most studies evaluate the impact of their natural or synthetic ligands on cell proliferation, death and differentiation. The putative natural PPAR $\gamma$ agonist, 15dPGJ2, inhibits cellular growth, decreases cellular viability and induces apoptosis in human neuroblastoma cells in vitro $[100,103,104]$, although some effects have been demonstrated to be PPAR $\gamma$-independent [105]. Rodway et al. [103] showed that the PPAR $\alpha$ agonist WY-14643 has no effect on the growth of the IMR32 neuroblastoma cell line, whereas PGJ2 induces growth inhibition in the same neuroblastoma cells. This occurs through programmed cell death type II or autophagy, and the serum lysolipid, the lysophosphatidic acid (LPA), is responsible for modulating this cellular response. In the neuroblastoma cell line ND-7, the same group showed that the degree of PPAR $\gamma$ activation induced by PGJ2 is modulated through an interaction with the retinoblastoma protein $(\mathrm{Rb})$ and histone deacetylase [106]. A combination therapy consisting of PGJ2 and the histone deacetylase inhibitor trichostatin A enhances the growth inhibition effects and is therefore proposed as a promising new strategy in the treatment of neuroblastoma. It should be noted that the effects of 15d-PGJ2 can also depend on its action on the $\mathrm{NF} \kappa \mathrm{B}$ pathway [107]. Valentiner et al. [108] tested four synthetic PPAR $\gamma$ TZD agonists (ciglitazone, pioglitazone, troglitazone, rosiglitazone) and reported their in vitro effects on cell growth of seven human neuroblastoma cell lines (Kelly, LAN-1, LAN-5, LS, IMR-32, SK-N-SH, and SH-SY5Y). All TZDs inhibited cell growth and viability of the cells in a dose-dependent manner, whereas the effectiveness of the single drugs was strongly different among cell lines. Similar results for ciglitazone and rosiglitazone have been reported [100, 109]. Cellai and colleagues [109] showed that high concentrations of rosiglitazone in vitro significantly inhibit cell adhesion, invasiveness, and apoptosis in SK-NAS, but not in SH-SY5Y human neuroblastoma cells. The authors argued that this effect may be related to cellular differences in PPAR $\gamma$ transactivation. We have recently demonstrated [110] that PPAR $\beta / \delta$ agonists, both natural and synthetic (oleic acid and GW0742, respectively), are able to induce cell cycle arrest in G1 phase and neuronal differentiation in human neuroblastoma cell line SH-NH-5YSY by increasing p16 levels and decreasing cyclin D1 levels as well as by inducing the expression of neuronal differentiation markers and downregulating $\operatorname{Tr} \kappa \mathrm{B}$ full length expression. In the case of neuroblastoma, both PPAR $\gamma$ and PPAR $\beta / \delta$ ligands showed antiproliferative effects but it should be noted that PPAR $\gamma$ activation results in apoptosis promotion, while $\operatorname{PPAR} \beta / \delta$ activation results in cell cycle arrest and neuronal differentiation, thus suggesting the possibility to use dual agonists to counteract tumor progression and recurrences.

\section{Future Perspectives}

The majority of malignant neuroepithelial tumors have poor prognosis and do not respond to conventional therapeutic protocols. Studying and validating both natural and synthetic PPAR ligands may represent a starting point for the formulation of new therapeutic approaches to be used as coadjuvants to the standard therapeutic protocols. Another point to be considered is the targeting efficiency of these new drugs. The progress in the understanding of the biology and genetic of neuroepithelial tumors together with the use of truly manipulable experimental models, now offer real opportunities for the development of effective targeted therapy. Despite significant gaps in our understanding, a wealth of information now exists about the clinical and biological behaviours of these tumors, the genetic pathways involved in tumorigenesis, and the nature and role of signature alterations in these pathways. The challenge now is to integrate this knowledge in an interdisciplinary way to fully understand these diseases, particularly how their signature heterogeneity contributes to their intractability in order to design efficient drugs delivered exclusively to malignant cells.

\section{References}

[1] W. K. Cavenee, F. B. Furnari, M. Nagane, et al., "Diffusely infiltrating astrocytomas," in Pathology and Genetics of Tumours of the Nervous System, P. Kleihues and W. K. Cavenee, Eds., pp. 10-21, International Agency for Research on Cancer, Lyon, France, 2000.

[2] P. C. Burger, B. W. Scheithauer, W. Paulus, et al., "Pilocytic astrocytoma," in Pathology and Genetics of Tumours of the Nervous System, P. Kleihues and W. K. Cavenee, Eds., pp. 45-51, International Agency for Research on Cancer, Lyon, France, 2000.

[3] P. Kleihues, R. L. Davis, H. Ohgaki, et al., "Diffuse astrocytoma," in Pathology and Genetics of Tumours of the Nervous System, P. Kleihues and W. K. Cavenee, Eds., pp. 22-26, International Agency for Research on Cancer, Lyon, France, 2000.

[4] G. J. Kitange, K. L. Templeton, and R. B. Jenkins, "Recent advances in the molecular genetics of primary gliomas," Current Opinion in Oncology, vol. 15, no. 3, pp. 197-203, 2003.

[5] P. Kleihues, R. L. Davis, S. W. Coons, et al., "Anaplastic astrocytoma," in Pathology and Genetics of Tumours of the Nervous System, P. Kleihues and W. K. Cavenee, Eds., pp. 27-28, International Agency for Research on Cancer, Lyon, France, 2000.

[6] P. Kleihues, P. C. Burger, V. P. Collins, et al., "Glioblastoma," in Pathology and Genetics of Tumours of the Nervous System, P. Kleihues and W. K. Cavenee, Eds., pp. 29-39, International Agency for Research on Cancer, Lyon, France, 2000. 
[7] J. G. Gurney and N. Kadan-Lottick, "Brain and other central nervous system tumors: rates, trends, and epidemiology," Current Opinion in Oncology, vol. 13, no. 3, pp. 160-166, 2001.

[8] H. Jiang, C. Conrad, J. Fueyo, C. Gomez-Manzano, and T. J. Liu, "Oncolytic adenoviruses for malignant glioma therapy," Frontiers in Bioscience, vol. 8, pp. d577-d588, 2003.

[9] X. Fan, Y. Aalto, S. G. Sanko, S. Knuutila, D. Klatzmann, and J. S. Castresana, "Genetic profile, PTEN mutation and therapeutic role of PTEN in glioblastomas," International Journal of Oncology, vol. 21, no. 5, pp. 1141-1150, 2002.

[10] N. Ishii, D. Maier, A. Merlo, et al., "Frequent co-alteration of TP53, p16/CDKN 2S, p14ARF, PTEN tumor suppressor genes in human glioblastoma cell lines," Brain Pathology, vol. 9, pp. 469-479, 1999.

[11] P. Kleihues and W. K. Cavenee, Eds., Pathology and Genetics of Tumours of the Nervous System, International Agency for Research on Cancer, Lyon, France, 2000.

[12] P. Kleihues, D. N. Louis, B. W. Scheithauer, et al., "The WHO classification of tumors of the nervous system," Journal of Neuropathology and Experimental Neurology, vol. 61, no. 3, pp. 215-225, 2002.

[13] D. A. Reardon, J. N. Rich, H. S. Friedman, and D. D. Bigner, "Recent advances in the treatment of malignant astrocytoma," Journal of Clinical Oncology, vol. 24, no. 8, pp. 1253-1265, 2006.

[14] G. M. Brodeur, R. C. Seeger, M. Schwab, H. E. Varmus, and J. M. Bishop, "Amplification of N-myc in untreated human neuroblastomas correlates with advanced disease stage," Science, vol. 224, no. 4653, pp. 1121-1124, 1984.

[15] National Cancer Institute, "Surveillance, Epidemiology and End Results Database," November, 2005, http://seer.cancer.gov/.

[16] M. Schwab, G. P. Tonini, and J. Benard, Human Neuroblastoma. Recent Advances in Clinical and Genetic Analysis, Harwood Academic Publishers, Chur, Switzerland, 1993.

[17] R. C. Seeger, G. M. Brodeur, H. Sather, et al., "Association of multiple copies of the N-myc oncogene with rapid progression of neuroblastomas," The New England Journal of Medicine, vol. 313, no. 18, pp. 1111-1116, 1985.

[18] P. S. White, P. M. Thompson, B. A. Seifried, et al., "Detailed molecular analysis of 1p36 in neuroblastoma," Medical and Pediatric Oncology, vol. 36, no. 1, pp. 37-41, 2001.

[19] P. S. White, P. M. Thompson, T. Gotoh, et al., "Definition and characterization of a region of $1 \mathrm{p} 36.3$ consistently deleted in neuroblastoma," Oncogene, vol. 24, no. 16, pp. 2684-2694, 2005.

[20] N. Sidell, "Retinoic acid-induced growth inhibition and morphologic differentiation of human neuroblastoma cells in vitro," Journal of the National Cancer Institute, vol. 68, no. 4, pp. 589-596, 1982.

[21] J. L. Biedler, L. Helson, and B. A. Spengler, "Morphology and growth, tumorigenicity, and cytogenetics of human neuroblastoma cells in continuous culture," Cancer Research, vol. 33, no. 11, pp. 2643-2652, 1973.

[22] S. Pahlman, L. Odelstad, E. Larsson, G. Grotte, and K. Nilsson, "Phenotypic changes of human neuroblastoma cells in culture induced by 12-O-tetradecanoyl-phorbol-13acetate," International Journal of Cancer, vol. 28, no. 5, pp. 583-589, 1981.

[23] V. Parrow, E. Nanberg, J. Heikkila, U. Hammerling, and S. Pahlman, "Protein kinase $\mathrm{C}$ remains functionally active during TPA induced neuronal differentiation of SH-SY5Y human neuroblastoma cells," Journal of Cellular Physiology, vol. 152, no. 3, pp. 536-544, 1992.

[24] S. Fagerström, S. Påhlman, C. Gestblom, and E. Nånberg, "Protein kinase C- $\varepsilon$ is implicated in neurite outgrowth in differentiating human neuroblastoma cells," Cell Growth and Differentiation, vol. 7, no. 6, pp. 775-785, 1996.

[25] J. van Wijk, B. Coll, M. C. Cabezas, et al., "Rosiglitazone modulates fasting and post-prandial paraoxonase 1 activity in type 2 diabetic patients," Clinical and Experimental Pharmacology and Physiology, vol. 33, no. 12, pp. 1134-1137, 2006.

[26] W. Linz, P. Wohlfart, M. Baader, et al., "The peroxisome proliferator-activated receptor- $\alpha$ (PPAR- $\alpha$ ) agonist, AVE8134, attenuates the progression of heart failure and increases survival in rats," Acta Pharmacologica Sinica, vol. 30, no. 7, pp. 935-946, 2009.

[27] A. Galli, T. Mello, E. Ceni, E. Surrenti, and C. Surrenti, "The potential of antidiabetic thiazolidinediones for anticancer therapy," Expert Opinion on Investigational Drugs, vol. 15, no. 9, pp. 1039-1049, 2006.

[28] I. Issemann and S. Green, "Activation of a member of the steroid hormone receptor superfamily by peroxisome proliferators," Nature, vol. 347, no. 6294, pp. 645-650, 1990.

[29] C. Dreyer, G. Krey, H. Keller, F. Givel, G. Helftenbein, and W. Wahli, "Control of the peroxisomal $\beta$-oxidation pathway by a novel family of nuclear hormone receptors," Cell, vol. 68, no. 5, pp. 879-887, 1992.

[30] J. N. Feige, L. Gelman, L. Michalik, B. Desvergne, and W. Wahli, "From molecular action to physiological outputs: peroxisome proliferator-activated receptors are nuclear receptors at the crossroads of key cellular functions," Progress in Lipid Research, vol. 45, no. 2, pp. 120-159, 2006.

[31] R. T. Nolte, G. B. Wisely, S. Westin, et al., "Ligand binding and co-activator assembly of the peroxisome proliferatoractivated receptor- $\gamma$," Nature, vol. 395, no. 6698, pp. 137-143, 1998.

[32] S. Kersten and W. Wahli, "Peroxisome proliferator activated receptor agonists," EXS, vol. 89, pp. 141-151, 2000.

[33] T. M. Willson, P. J. Brown, D. D. Sternbach, and B. R. Henke, "The PPARs: from orphan receptors to drug discovery," Journal of Medicinal Chemistry, vol. 43, no. 4, pp. 527-550, 2000.

[34] J. P. Vanden Heuvel, "Peroxisome proliferator-activated receptors: a critical link among fatty acids, gene expression and carcinogenesis," Journal of Nutrition, vol. 129, supplement 2, pp. 575S-580S, 1999.

[35] A. Cimini, L. Cristiano, A. Bernardo, S. Farioli-Vecchioli, S. Stefanini, and M. P. Cerù, "Presence and inducibility of peroxisomes in a human glioblastoma cell line," Biochimica et Biophysica Acta, vol. 1474, no. 3, pp. 397-409, 2000.

[36] M. T. Heneka and G. E. Landreth, "PPARs in the brain," Biochimica et Biophysica Acta, vol. 1771, no. 8, pp. 1031-1045, 2007.

[37] Y. Barak, Y. Sadovsky, and T. Shalom-Barak, "PPAR signaling in placental development and function," PPAR Research, vol. 2008, Article ID 142082, 11 pages, 2008.

[38] P. Escher and W. Wahli, "Peroxisome proliferator-activated receptors: insight into multiple cellular functions," Mutation Research, vol. 448, no. 2, pp. 121-138, 2000.

[39] J. M. Keller, P. Collet, A. Bianchi, et al., "Implications of peroxisome proliferator-activated receptors (PPARS) in development, cell life status and disease," International Journal of Developmental Biology, vol. 44, no. 5, pp. 429-442, 2000. 
[40] P. Escher, O. Braissant, S. Basu-Modak, L. Michalik, W. Wahli, and B. Desvergne, "Rat PPARs: quantitative analysis in adult rat tissues and regulation in fasting and refeeding," Endocrinology, vol. 142, no. 10, pp. 4195-4202, 2001.

[41] Y. Shi, M. Hon, and R. M. Evans, "The peroxisome proliferator-activated receptor $\delta$, an integrator of transcriptional repression and nuclear receptor signaling," Proceedings of the National Academy of Sciences of the United States of America, vol. 99, no. 5, pp. 2613-2618, 2002.

[42] C. Bastie, "PPAR $\delta$ and PPAR $\gamma$ : roles in fatty acids signalling, implication in tumorigenesis," Bulletin du Cancer, vol. 89, no. 1, pp. 23-28, 2002.

[43] L. Michalik, B. Desvergne, and W. Wahli, "Peroxisome proliferator-activated receptors $\beta / \delta$ : emerging roles for a previously neglected third family member," Current Opinion in Lipidology, vol. 14, no. 2, pp. 129-135, 2003.

[44] T. Lemberger, B. Desvergne, and W. Wahli, "Peroxisome proliferator-activated receptors: a nuclear receptor signaling pathway in lipid physiology," Annual Review of Cell and Developmental Biology, vol. 12, pp. 335-363, 1996.

[45] J. Berger and D. E. Moller, "The mechanisms of action of PPARs," Annual Review of Medicine, vol. 53, pp. 409-435, 2002.

[46] H. A. Hostetler, A. D. Petrescu, A. B. Kier, and F. Schroeder, "Peroxisome proliferator-activated receptor $\alpha$ interacts with high affinity and is conformationally responsive to endogenous ligands," The Journal of Biological Chemistry, vol. 280, no. 19, pp. 18667-18682, 2005.

[47] F. J. Schopfer, Y. Lin, P. R. S. Baker, et al., "Nitrolinoleic acid: an endogenous peroxisome proliferator-activated receptor $\gamma$ ligand," Proceedings of the National Academy of Sciences of the United States of America, vol. 102, no. 7, pp. 2340-2345, 2005.

[48] T. Shiraki, N. Kamiya, S. Shiki, T. S. Kodama, A. Kakizuka, and H. Jingami, " $\alpha, \beta$-unsaturated ketone is a core moiety of natural ligands for covalent binding to peroxisome proliferator-activated receptor $\gamma$," The Journal of Biological Chemistry, vol. 280, no. 14, pp. 14145-14153, 2005.

[49] N.-S. Tan, N. S. Shaw, N. Vinckenbosch, et al., "Selective cooperation between fatty acid binding proteins and peroxisome proliferator-activated receptors in regulating transcription," Molecular and Cellular Biology, vol. 22, no. 14, pp. 5114-5127, 2002.

[50] C. Grommes, G. E. Landreth, and M. T. Heneka, "Antineoplastic effects of peroxisome proliferator-activated receptor $\gamma$ agonists," Lancet Oncology, vol. 5, no. 7, pp. 419-429, 2004.

[51] P. Tontonoz, S. Singer, B. M. Forman, et al., "Terminal differentiation of human liposarcoma cells induced by ligands for peroxisome proliferator-activated receptor $\gamma$ and the retinoid X receptor," Proceedings of the National Academy of Sciences of the United States of America, vol. 94, no. 1, pp. 237-241, 1997.

[52] E. Elstner, C. Müller, K. Koshizuka, et al., "Ligands for peroxisome proliferator-activated receptor $\gamma$ and retinoic acid receptor inhibit growth and induce apoptosis of human breast cancer cells in vitro and in BNX mice," Proceedings of the National Academy of Sciences of the United States of America, vol. 95, no. 15, pp. 8806-8811, 1998.

[53] E. Mueller, P. Sarraf, P. Tontonoz, et al., "Terminal Differentiation of Human Breast Cancer through PPAR $y$," Molecular Cell, vol. 1, no. 3, pp. 465-470, 1998.

[54] T. Kubota, K. Koshizuka, E. A. Williamson, et al., "Ligand for peroxisome proliferator-activated receptor $\gamma$ (Troglitazone) has potent antitumor effect against human prostate cancer both in vitro and in vivo," Cancer Research, vol. 58, no. 15, pp. 3344-3352, 1998.
[55] J. A. Brockman, R. A. Gupta, and R. N. Dubois, "Activation of PPAR $\gamma$ leads to inhibition of anchorage-independent growth of human colorectal cancer cells," Gastroenterology, vol. 115, no. 5, pp. 1049-1055, 1998.

[56] P. Sarraf, E. Mueller, D. Jones, et al., "Differentiation and reversal of malignant changes in colon cancer through PPARy," Nature Medicine, vol. 4, no. 9, pp. 1046-1052, 1998.

[57] T.-H. Chang and E. Szabo, "Induction of differentiation and apoptosis by ligands of peroxisome proliferator-activated receptor $\gamma$ in non-small cell lung cancer," Cancer Research, vol. 60 , no. 4 , pp. 1129-1138, 2000.

[58] W. Motomura, T. Okumura, N. Takahashi, T. Obara, and Y. Kohgo, "Activation of peroxisome proliferator-activated receptor $\gamma$ by troglitazone inhibits cell growth through the increase of p27(Kip1) in human pancreatic carcinoma cells," Cancer Research, vol. 60, no. 19, pp. 5558-5564, 2000.

[59] Y.-F. Guan, Y.-H. Zhang, R. M. Breyer, L. Davis, and M. D. Breyer, "Expression of peroxisome proliferator-activated receptor $\gamma(\operatorname{PPAR} \gamma)$ in human transitional bladder cancer and its role in inducing cell death," Neoplasia, vol. 1, no. 4, pp. 330-339, 1999.

[60] H. Sato, S. Ishihara, K. Kawashima, et al., "Expression of peroxisome proliferator-activated receptor (PPAR) $\gamma$ in gastric cancer and inhibitory effects of PPAR $\gamma$ agonists," British Journal of Cancer, vol. 83, no. 10, pp. 1394-1400, 2000.

[61] O. Braissant, F. Foufelle, C. Scotto, M. Dauca, and W. Wahli, "Differential expression of peroxisome proliferator-activated receptors (PPARs): tissue distribution of PPAR- $\alpha,-\beta$, and $-\gamma$ in the adult rat," Endocrinology, vol. 137, no. 1, pp. 354-366, 1996.

[62] S. Basu-Modak, O. Braissant, P. Escher, B. Desvergne, P. Honegger, and W. Wahli, "Peroxisome proliferator-activated receptor $\beta$ regulates acyl-CoA synthetase 2 in reaggregated rat brain cell cultures," The Journal of Biological Chemistry, vol. 274, no. 50, pp. 35881-35888, 1999.

[63] J. R. Marszalek, C. Kitidis, A. Dararutana, and H. F. Lodish, "Acyl-CoA synthetase 2 overexpression enhances fatty acid internalization and neurite outgrowth," The Journal of Biological Chemistry, vol. 279, no. 23, pp. 23882-23891, 2004.

[64] J. M. Peters, S. S. T. Lee, W. Li, et al., "Growths, adipose, brain, and skin alterations resulting from targeted disruption of the mouse peroxisome proliferator-activated receptor $\beta(\delta)$," Molecular and Cellular Biology, vol. 20, no. 14, pp. 5119-5128, 2000.

[65] L. Michalik, B. Desvergne, C. Dreyer, M. Gavillet, R. N. Laurini, and W. Wahli, "PPAR expression and function during vertebrate development," International Journal of Developmental Biology, vol. 46, no. 1, pp. 105-114, 2002.

[66] A. Cimini, E. Benedetti, L. Cristiano, et al., "Expression of peroxisome proliferator-activated receptors (PPARs) and retinoic acid receptors (RXRs) in rat cortical neurons," Neuroscience, vol. 130, no. 2, pp. 325-337, 2005.

[67] J. W. Woods, M. Tanen, D. J. Figueroa, et al., "Localization of PPAR $\delta$ in murine central nervous system: expression in oligodendrocytes and neurons," Brain Research, vol. 975, no. 1-2, pp. 10-21, 2003.

[68] S. Moreno, S. Farioli-vecchioli, and M. P. Cerù, "Immunolocalization of peroxisome proliferator-activated receptors and retinoid X receptors in the adult rat CNS," Neuroscience, vol. 123, no. 1, pp. 131-145, 2004.

[69] A. Benani, P. Krémarik-Bouillaud, A. Bianchi, P. Netter, A. Minn, and M. Dauça, "Evidence for the presence of both peroxisome proliferator-activated receptors alpha and beta in 
the rat spinal cord," Journal of Chemical Neuroanatomy, vol. 25, no. 1, pp. 29-38, 2003.

[70] J. Granneman, R. Skoff, and X. Yang, "Member of the peroxisome proliferator-activated receptor family of transcription factors is differentially expressed by oligodendrocytes," Journal of Neuroscience Research, vol. 51, no. 5, pp. 563-573, 1998.

[71] I. Saluja, J. G. Granneman, and R. P. Skoff, "PPAR $\delta$ agonists stimulate oligodendrocyte differentiation in tissue culture," Glia, vol. 33, no. 3, pp. 191-204, 2001.

[72] A. Bernardo, M. A. Ajmone-Cat, G. Levi, and L. Minghetti, " 15 -deoxy- $\Delta^{12,14}$-prostaglandin $\mathrm{J}_{2}$ regulates the functional state and the survival of microglial cells through multiple molecular mechanisms," Journal of Neurochemistry, vol. 87, no. 3, pp. 742-751, 2003.

[73] T. E. Cullingford, K. Bhakoo, S. Peuchen, C. T. Dolphin, R. Patel, and J. B. Clark, "Distribution of mRNAs encoding the peroxisome proliferator-activated receptor $\alpha, \beta$, and $\gamma$ and the retinoid $\mathrm{X}$ receptor $\alpha, \beta$, and $\gamma$ in rat central nervous system," Journal of Neurochemistry, vol. 70, no. 4, pp. 13661375, 1998.

[74] L. Cristiano, A. Bernardo, and M. P. Cerù, "Peroxisome proliferator-activated receptors (PPARs) and peroxisomes in rat cortical and cerebellar astrocytes," Journal of Neurocytology, vol. 30, no. 8, pp. 671-683, 2001.

[75] L. Cristiano, A. Cimini, S. Moreno, A. M. Ragnelli, and M. P. Cerù, "Peroxisome proliferator-activated receptors (PPARs) and related transcription factors in differentiating astrocyte cultures," Neuroscience, vol. 131, no. 3, pp. 577-587, 2005.

[76] A. Cimini, L. Cristiano, E. Benedetti, B. D’Angelo, and M. P. Cerù, "PPARs expression in adult mouse neural stem cells: modulation of PPARs during astroglial differentiaton of NSC," PPAR Research, vol. 2007, Article ID 48242, 10 pages, 2007.

[77] A. Cimini and M. P. Cerù, "Emerging roles of peroxisome proliferator-activated receptors (PPARs) in the regulation of neural stem cells proliferation and differentiation," Stem Cell Reviews, vol. 4, no. 4, pp. 293-303, 2008.

[78] S. Farioli-Vecchioli, S. Moreno, and M. P. Cerù, "Immunocytochemical localization of acyl-CoA oxidase in the rat central nervous system," Journal of Neurocytology, vol. 30, no. 1, pp. 21-33, 2001.

[79] M. T. Heneka, T. Klockgether, and D. L. Feinstein, "Peroxisome proliferator-activated receptor- $\gamma$ ligands reduce neuronal inducible nitric oxide synthase expression and cell death in vivo," Journal of Neuroscience, vol. 20, no. 18, pp. 6862-6867, 2000.

[80] O. Braissant and W. Wahli, "Differential expression of peroxisome proliferator-activated receptor- $\alpha,-\beta$, and $-\gamma$ during rat embryonic development," Endocrinology, vol. 139, no. 6, pp. 2748-2754, 1998.

[81] A. Cimini, E. Benedetti, L. Cristiano, et al., "Expression of peroxisome proliferator-activated receptors (PPARs) and retinoic acid receptors (RXRs) in rat cortical neurons," Neuroscience, vol. 130, no. 2, pp. 325-337, 2005.

[82] C. Grommes, G. E. Landreth, U. Schlegel, and M. T. Heneka, "The nonthiazolidinedione tyrosine-based peroxisome proliferator-activated receptor $\gamma$ ligand GW7845 induces apoptosis and limits migration and invasion of rat and human glioma cells," Journal of Pharmacology and Experimental Therapeutics, vol. 313, no. 2, pp. 806-813, 2005.

[83] T. Zander, J. A. Kraus, C. Grommes, et al., "Induction of apoptosis in human and rat glioma by agonists of the nuclear receptor PPAR $\gamma$," Journal of Neurochemistry, vol. 81, no. 5, pp. 1052-1060, 2002.
[84] J. M. Pérez-Ortiz, P. Tranque, C. F. Vaquero, et al., "Glitazones differentially regulate primary astrocyte and glioma cell survival: involvement of reactive oxygen species and peroxisome proliferator-activated receptor- $\gamma$," The Journal of Biological Chemistry, vol. 279, no. 10, pp. 8976-8985, 2004.

[85] K. Berge, K. J. Tronstad, E. N. Flindt, et al., "Tetradecylthioacetic acid inhibits growth of rat glioma cells ex vivo and in vivo via PPAR-dependent and PPAR-independent pathways," Carcinogenesis, vol. 22, no. 11, pp. 1747-1755, 2001.

[86] C. Grommes, G. E. Landreth, M. Sastre, et al., "Inhibition of in vivo glioma growth and invasion by peroxisome proliferator-activated receptor $\gamma$ agonist treatment," Molecular Pharmacology, vol. 70, no. 5, pp. 1524-1533, 2006.

[87] N. Chattopadhyay, D. P. Singh, O. Heese, et al., "Expression of peroxisome proliferator-activated receptors (PPARs) in human astrocytic cells: PPAR $y$ agonists as inducers of apoptosis," Journal of Neuroscience Research, vol. 61, no. 1, pp. $67-74,2000$.

[88] R. Morosetti, T. Servidei, M. Mirabella, et al., "The PPAR $\gamma$ ligands PGJ2 and rosiglitazone show a differential ability to inhibit proliferation and to induce apoptosis and differentiation of human glioblastoma cell lines," International Journal of Oncology, vol. 25, no. 2, pp. 493-502, 2004.

[89] A. Cimini, L. Cristiano, S. Colafarina, et al., "PPAR $\gamma$ dependent effects of conjugated linoleic acid on the human glioblastoma cell line (ADF)," International Journal of Cancer, vol. 117, no. 6, pp. 923-933, 2005.

[90] A. Spagnolo, E. N. Grant, R. Glick, T. Lichtor, and D. L. Feinstein, "Differential effects of PPAR $\gamma$ agonists on the metabolic properties of gliomas and astrocytes," Neuroscience Letters, vol. 417, no. 1, pp. 72-77, 2007.

[91] E. Benedetti, R. Galzio, B. Cinque, et al., "Biomolecular characterization of human glioblastoma cells in primary cultures: differentiating and antiangiogenic effects of natural and synthetic PPAR $\gamma$ agonists," Journal of Cellular Physiology, vol. 217, no. 1, pp. 93-102, 2008.

[92] N. Strakova, J. Ehrmann, J. Bartos, J. Malikova, J. Dolezel, and Z. Kolar, "Peroxisome proliferator-activated receptors (PPAR) agonists affect cell viability, apoptosis and expression of cell cycle related proteins in cell lines of glial brain tumors," Neoplasma, vol. 52, no. 2, pp. 126-136, 2005.

[93] R. Coras, A. Hölsken, S. Seufert, et al., "The peroxisome proliferator-activated receptor- $\gamma$ agonist troglitazone inhibits transforming growth factor- $\beta$-mediated glioma cell migration and brain invasion," Molecular Cancer Therapeutics, vol. 6, no. 6, pp. 1745-1754, 2007.

[94] N. Yamada, M. Kato, H. Yamashita, et al., "Enhanced expression of transforming growth factor- $\beta$ and its type-I and type-II receptors in human glioblastoma," International Journal of Cancer, vol. 62, no. 4, pp. 386-392, 1995.

[95] T. Kawataki, H. Naganuma, A. Sasaki, H. Yoshikawa, K. Tasaka, and H. Nukui, "Correlation of thrombospondin-1 and transforming growth factor- $\beta$ expression with malignancy of glioma," Neuropathology, vol. 20, no. 3, pp. 161-169, 2000.

[96] H. Walczak, R. E. Miller, K. Ariail, et al., "Tumoricidal activity of tumor necrosis factor-related apoptosis-inducing ligand in vivo," Nature Medicine, vol. 5, no. 2, pp. 157-163, 1999.

[97] A. Ashkenazi, R. C. Pai, S. Fong, et al., "Safety and antitumor activity of recombinant soluble Apo2 ligand," Journal of Clinical Investigation, vol. 104, no. 2, pp. 155-162, 1999.

[98] K. Schultze, B. Böck, A. Eckert, et al., "Troglitazone sensitizes tumor cells to TRAIL-induced apoptosis via down-regulation 
of FLIP and Survivin," Apoptosis, vol. 11, no. 9, pp. 15031512, 2006.

[99] E. Benedetti, R. Galzio, G. Laurenti, et al., "Lipid metabolism impairment in human gliomas: expression of peroxisomal proteins in human gliomas at different grades of malignancy," International Journal of Immunopathology and Pharmacology. In press.

[100] T. Servidei, R. Morosetti, C. Ferlini, et al., "The cellular response to PPAR $y$ ligands is related to the phenotype of neuroblastoma cell lines," Oncology Research, vol. 14, no. 78, pp. 345-354, 2004.

[101] A. O. Isaac, I. Kawikova, A. L. M. Bothwell, C. K. Daniels, and J. C. K. Lai, "Manganese treatment modulates the expression of peroxisome proliferator-activated receptors in astrocytoma and neuroblastoma cells," Neurochemical Research, vol. 31, no. 11, pp. 1305-1316, 2006.

[102] S. Falone, M. R. Grossi, B. Cinque, et al., "Fifty hertz extremely low-frequency electromagnetic field causes changes in redox and differentiative status in neuroblastoma cells," International Journal of Biochemistry and Cell Biology, vol. 39, no. 11, pp. 2093-2106, 2007.

[103] H. A. Rodway, A. N. Hunt, J. A. Kohler, A. D. Postle, and K. A. Lillycrop, "Lysophosphatidic acid attenuates the cytotoxic and degree of peroxisome proliferator-activated receptor $\gamma$ activation induced by 15 -deoxy $\Delta^{12,14}$-prostaglandin $\mathrm{J}_{2}$ in neuroblastoma cells," Biochemical Journal, vol. 382, no. 1, pp. 83-91, 2004.

[104] S. W. Han, M. E. Greene, J. Pitts, R. K. Wada, and N. Sidell, "Novel expression and function of peroxisome proliferatoractivated receptor $\gamma(\operatorname{PPAR} \gamma)$ in human neuroblastoma cells," Clinical Cancer Research, vol. 7, no. 1, pp. 98-104, 2001.

[105] S. Giri, R. Rattan, A. K. Singh, and I. Singh, "The 15-deoxy$\delta 12,14$-prostaglandin $\mathrm{J}_{2}$ inhibits the inflammatory response in primary rat astrocytes via down-regulating multiple steps in phosphatidylinositol 3-kinase-akt-NF- $\kappa$ B-p300 pathway independent of peroxisome proliferator-activated receptor $\gamma$," Journal of Immunology, vol. 173, no. 8, pp. 5196-5208, 2004.

[106] V. C. Emmans, H. A. Rodway, A. N. Hunt, and K. A. Lillycrop, "Regulation of cellular processes by PPAR $\gamma$ ligands in neuroblastoma cells is modulated by the level of retinoblastoma protein expression," Biochemical Society Transactions, vol. 32, no. 5, pp. 840-842, 2004.

[107] A. Rossi, P. Kapahi, G. Natoli, et al., "Anti-inflammatory cyclopentenone prostaglandins are direct inhibitors of $\mathrm{I} \kappa \mathrm{B}$ kinase," Nature, vol. 403, no. 6765, pp. 103-108, 2000.

[108] U. Valentiner, M. Carlsson, R. Erttmann, H. Hildebrandt, and U. Schumacher, "Ligands for the peroxisome proliferator-activated receptor- $\gamma$ have inhibitory effects on growth of human neuroblastoma cells in vitro," Toxicology, vol. 213, no. 1-2, pp. 157-168, 2005.

[109] I. Cellai, S. Benvenuti, P. Luciani, et al., "Antineoplastic effects of rosiglitazone and PPAR $\gamma$ transactivation in neuroblastoma cells," British Journal of Cancer, vol. 95, no. 7, pp. 879-888, 2006.

[110] S. Di Loreto, B. D’Angelo, M. A. D’Amico, et al., “PPAR $\beta$ agonists trigger neuronal differentiation in the human neuroblastoma cell line SH-SY5Y," Journal of Cellular Physiology, vol. 211, no. 3, pp. 837-847, 2007. 


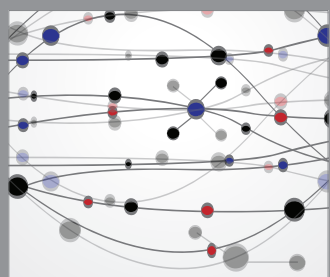

The Scientific World Journal
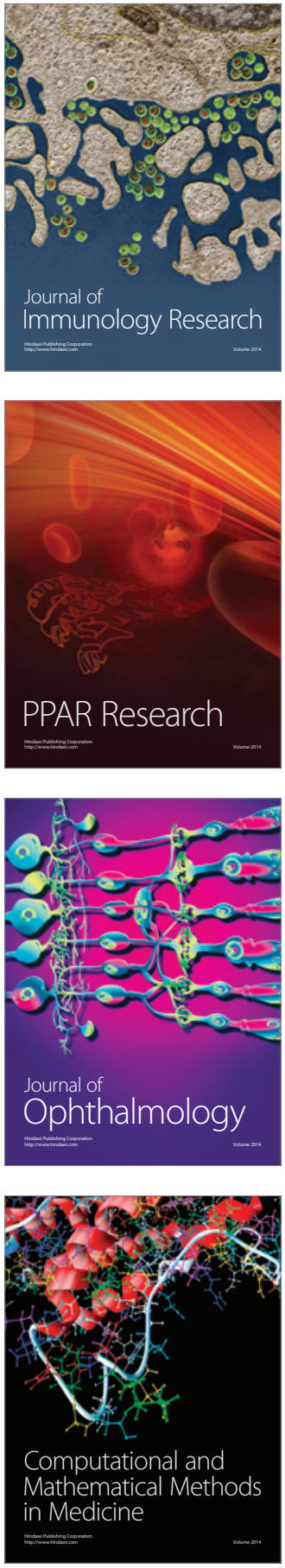

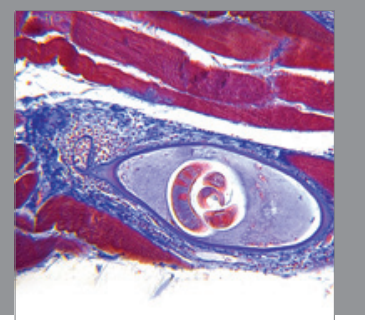

Gastroenterology

Research and Practice
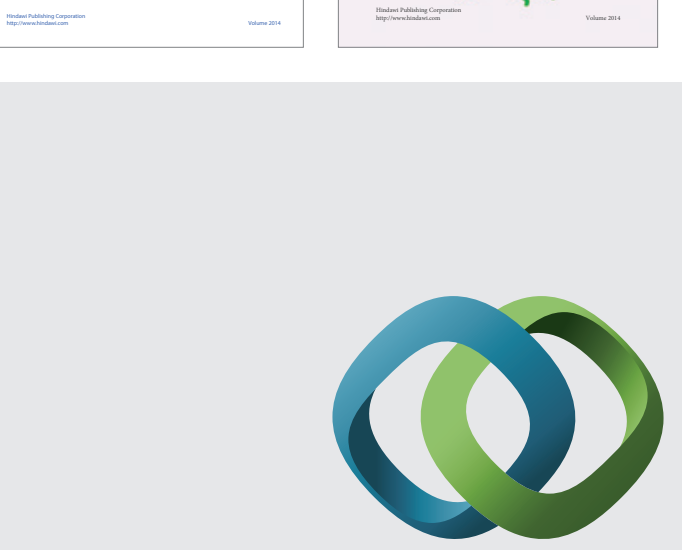

\section{Hindawi}

Submit your manuscripts at

http://www.hindawi.com
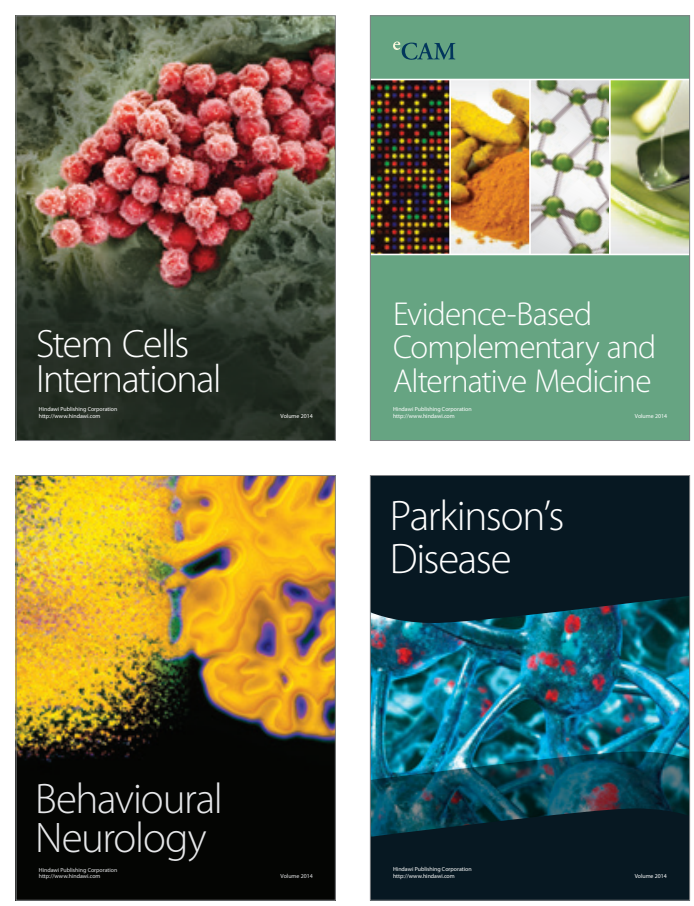

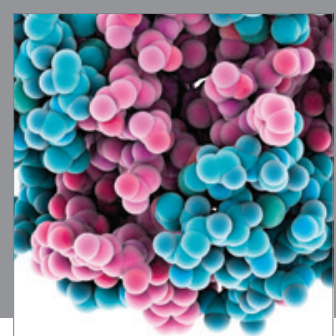

Journal of
Diabetes Research

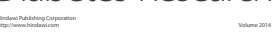

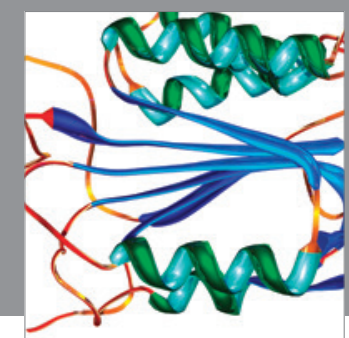

Disease Markers
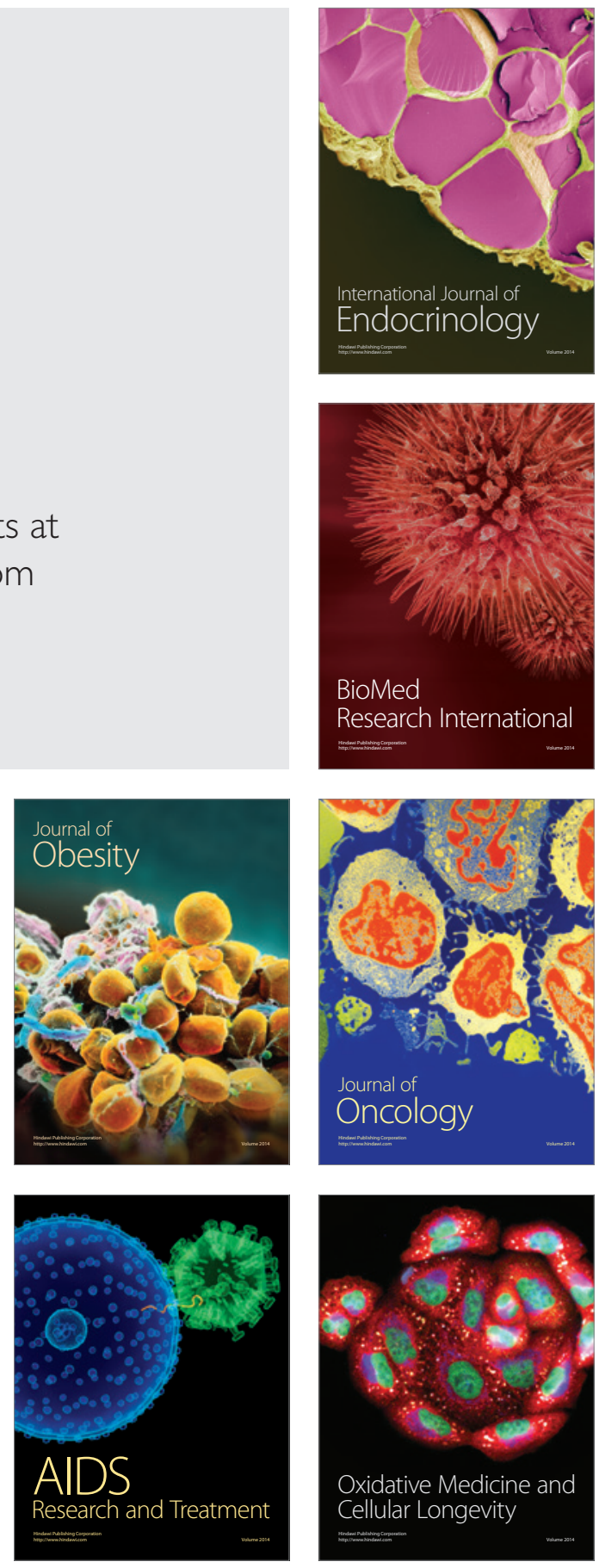